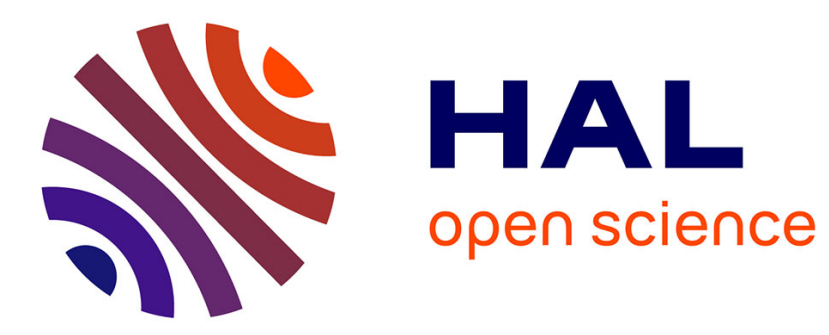

\title{
Social networks and normative tensions
}

\author{
Alexis Ferrand, Tom Snijders
}

\section{To cite this version:}

Alexis Ferrand, Tom Snijders. Social networks and normative tensions. Van Campenhoudt L., Cohen M., Guizzardi G., Hauser D,. Sexual interactions and HIV risk: new conceptual perspectives in European research, London, Taylor \& Francis, pp.6-21, 1997. halshs-00264362

\section{HAL Id: halshs-00264362 \\ https://shs.hal.science/halshs-00264362}

Submitted on 16 Mar 2008

HAL is a multi-disciplinary open access archive for the deposit and dissemination of scientific research documents, whether they are published or not. The documents may come from teaching and research institutions in France or abroad, or from public or private research centers.
L'archive ouverte pluridisciplinaire HAL, est destinée au dépôt et à la diffusion de documents scientifiques de niveau recherche, publiés ou non, émanant des établissements d'enseignement et de recherche français ou étrangers, des laboratoires publics ou privés. 


\title{
SOCIAL NETWORKS AND NORMATIVE TENSIONS
}

\author{
Alexis FERRAND, \\ LASMAS-CNRS, University of LILLE 1, F.
}

\section{Tom A.B. SNIJDERS}

ICS, University of GRONINGEN, NL

in Van Campenhoudt L., Cohen M., Guizzardi G., Hauser D, (eds)

Sexual interactions and HIV risk : new conceptual perspectives in European research, London, Taylor \& Francis, 1997, p.6-21.

Warning : This text is not exactly the final version published in the book

CONTENTS:

1. Introduction.

2. Sexual life as relational processes.

3. The influence of sociability on sexuality.

3.1. Effects of social context on sociability.

3.2. Mass communication and network effects.

4. Norms about safe sex.

4.1 Norms and sanctions.

4.2. How do norms come to exist and be maintained?

4.3. Information on sexual behaviour in social networks.

4.4. Network structure and information flow.

4.5. Communication and the emergence of norms.

5. Conclusion.

6. References 


\section{Introduction.}

The body is our fundamental and primary environment. It offers us pleasures and pains. Most often sexual activities induce pleasure, but they can also induce illness and pains. The basic terms of the individualistic approach to health-oriented sexual behaviour are the following. Other human beings are our secondary environment. They can offer different kinds of physical and non-physical pleasures and pains, because of who they are and how we are related to them. Among these pleasures, those implied by sexual relations are supposed to be the more enjoyable and rewarding ones.

This paper aims to transcend this individualistic approach, and stresses the relational dimension of sexual life in a sociological perspective. First we move from the notion of individual sexual behaviour to that of interpersonal relation - effectively or potentially sexualised. As all personal relations, sexual relations are embedded in personal networks. The relational perspective on sexual behaviour makes it necessary to understand how personal networks are formed and maintained, and which functions they can fulfill. Among these functions we emphasize the production and reinforcement of collective norms of sexual behaviour, conditioned by specific properties of networks.

2. Sexual life as relational processes.

The most characteristic feature of sexual life is the impulse, the feeling, the affectivity, between persons. Sexual life is made of links between pairs (or larger groups) of persons. These links can exist at several levels: at the level of physical contact as well as that of language, of interaction, etc., up to the level of the pure imaginary. Nobody can contest the general approach to analyse individual sexual life taking into account the orientation of ego toward alters in terms of mono/pluri partnership, homo/hetero sexual orientation, self-erotization (as a retreat from the encountering of alter), and so on.

Much research of sexual behaviour is based (often implicitly) on the paradigm of an actor open to his socio-sexual environment, trying to obtain from it the satisfaction of physical, psychological, or sociological sexual demands, in which paradigm this environment is treated as an inert context. Within this paradigm, sexual interactions are explained mainly by the psychological and sociological backgrounds of separate individuals and the constraints implied by these backgrounds. Actors are assumed to pick up more or less rewarding sexual partners from what their environment offers them, as objects of their conscious and unconscious strategies, and given the biological, psychological, sociological, economical, and other constraints. Such a separately considered individual is designated in this paper as the "focal actor".

This paradigm, however, raises a theoretical problem: if we assume a diversity of properties of the focal actor, properties which influence his/her strategies and actions, we have to explain why it is sufficient that the sexual partner's properties, which in turn influence his/her participation in sexual relations with the focal actor, be defined simply in very broad and rough terms (such as gender, age, social and marital status).

A relational theory of sexuality must re-introduce in its approach the symmetry between ego (focal actor) and alter (possible partner). Moreover, such a theory must recognize that the behaviour of actors (or couples) not only is restricted by the social context, but simultaneously influences and shapes the social context. All of us are egos to ourselves, and to others we are alters as well as components of the social context. An example of the last aspect is that everybody has a role of upholding social norms, a role which may be fulfilled in a specific way: strict, loose, deviant, ... The social environment therefore is not inert but in dynamic interaction with individuals. 
Such a relational theory of sexuality is complex. We prefer it because it has a better logical correspondence to the phenomena of sexual behaviour, because we hope it is also empirically more powerful, but not because it is more simple. This relational paradigm is grounded on a few basic postulates.

1) Dyadic nature of sexuality.

"Sexuality" is defined from the specific point of view of interactions between actors, with a focus on pairwise ("dyadic") interactions. The object of the theory is the variety of processes by which social interpersonal relations are sexualized. These various processes of sexualization are a specific domain in the broad field of interpersonal relations. Thus, the theoretical frame is partly the general frame of interpersonal relations, and partly specific to sexual behaviour.

\section{2) Anticipation on alter's reactions.}

Any relation is viewed as a sequence of interactions. Dyadic interactions are a specific kind of behaviour in which an individual ("ego") acts on the basis of expected and perceived answers of another individual ("alter"). Expectations are based as well on contextual social knowledge and norms as on remembered personal experiences and subjective expectations. Interactions involve reciprocal attempts of adjustment between both actors' expectations and behaviours.

3) Bargaining and change.

Implicit or explicit "bargaining" allows actors to define what is at the present moment pertinent for their relationship. This agreement can, and often does, change. Any relation is a process, and may be stable over a long period or rapidly changing. Different kinds of sexualization are steps in a whole relational process: they appear at certain moments, they can be transformed into different relational behaviour, and they can end.

4) Embeddedness of relations in networks.

For each actor, any relation is an element in his/her system of interpersonal relationships, the so-called ego network. A relation links two actors, and simultaneously takes part in the composition and structure of the two relational systems of the actors involved. In addition, others (i.e., third persons) can observe part of the relational behaviour of the two actors. This observation is incomplete and often distorted, but may influence the two actors as well as the other persons.

5) Flexibility of norms and values.

Social norms and socially determined expectations are not rigid. Individuals and social groups can and do adapt their norms and expectations in view of their preferences, constraints, and the information available to them. This holds also for norms and expectations that have a bearing on the ways in which relationships are sexualized. For example, when in many western countries the pill became available in the 1960's as a convenient new method of contraception, this implied a change in restrictions to (in this case, consequences of) sexual relations; this has led to important changes of behaviour and, eventually, changes of norms and expectations. The information that may give rise to changing norms and expectations can be of a public nature (e.g., generally available knowledge about the reliability of contraception methods) but can also be formed of personal experiences (e.g., having undergone an abortion).

Postulates 3 (bargaining) and 4 (embeddedness) imply a theoretical ambiguity of each relation: it must partly be understood as a specific relational process with its own history, and partly as an element in both egos' network structures. Clearly, at present, there does not exist a complete and explicit theory that integrates this ambiguity. Instead, the ambiguity is managed through partial, "middle range" propositions (on one hand based on the psycho-sociology of relational processes, on the other hand on the sociology of network structure). 
It is impossible to give here a thorough discussion of the implications and developments of these general postulates. We point only to some specific aspects.

1) "Sexualization" covers the whole range of interactions by which a relation can provide affective, physical, and social rewards defined by actors as "sexual": from platonic "rendezvous" to hard intercourse. Sexualization as a process, as a sequence of different kinds of interactions, is a central issue for prevention of health-endangering behaviour.

For example, often regardless of any new information about each other, sexual partners may abandon condom use simply because their relation, by its own existence, generates new conditions for self-continuation. The chance of HIV transmission through sexual contacts creates a contradiction between the durability of the objective risk attached to an infected person, and the dynamics of any interpersonal love relation: rapidly evolving reciprocal "trust" impedes partners to maintain safe sex conditions (PETO et al., 1992). As a not wholly different example, actors who meet socially since a bit of time often suppose they "know" each other's sexual life, and therefore don't have to take care when they engage in a mutual sexual relationship. Many people assume that their own social circle is "clean": social proximity is seen as guarantee. This illustrates again how the new situation created by the HIV epidemic has upset the balance between emotions, cognitions, and behaviour that regulates sexualization of social relations.

2) A study of sexuality along these lines cannot be based merely on cross-sections of behaviour, but must take into account the development of interaction processes. At a first glance the idea of studying the relational process, thereby identifying successive changes in relationships, seems of an enormous complexity and diversity: it is already difficult to propose a robust typology of instantaneous sexual behaviour. But we have to keep in mind that a prevention-oriented analysis is only possible on the basis of the study of relational processes, were it only because it is necessary to capture the change from condition "unsafe" to condition "safe", and from "safe" to "unsafe".

3) As a consequence, an actor does not have "a" behaviour: he/she may have several behaviours in a given relation through time, and several behaviours at a given time as a result of specific bargainings with different partners.

4) It follows from postulate 4 (embeddedness) that affective, symbolic, and social demands made by actors in a sexual relation depend also on actual and expected rewards in other possible sexual relations; and, more broadly, in other significant interpersonal ties. For example, routinization of leisure life and of social encountering can focus on exceptional sexual relations demands of change, uncertainty, and risk. Such a "compensation" is one of the many possible patterns.

5) Postulates 4 (embeddedness) and 5 (flexibility of norms) imply that there is a feed-back between actors' behaviour in a social system, mediated by a change of norms. When individuals perceive changes in sexualization patterns in the behaviour of others in their personal network, this will change their expectations and norms, which will in turn change their behaviour; this changed behaviour will feed back upon the behaviour of the others in their personal network. 


\section{The influence of sociability on sexuality.}

\subsection{Effects of social context on sociability.}

Since sexual relationships are a specific subset of interpersonal relations, we present some relevant general traits of sociability, i.e., of the general ways in which people relate to one another. Two important aspects of the social context are the following.

(A) Composition of the wider social surroundings (accessible geographical region, work place, etc.): demographic structure, composition with respect to social economic status, ethnic identities, etc. These surroundings are also the carrier of information disseminated by the mass media with respect to general features of the prevalence of sexually transmitted diseases, and provide a base value for the individual's estimates of the risks associated with various sexual activities. (B) The social network, i.e., the network of significant interpersonal ties in which ego's social network is embedded. This network may be regarded as the carrier of norms about behaviour and of more specific information about individuals infected with sexually transmitted diseases, etc.

Aspect (A) is taken into account by the firstly mentionned paradigm in section 2 as global contextual variable wich constraints individuals ; the rejection of this paradigm means that aspect (B) with all its consequences should also be taken into account, not that aspect (A) should be negated.

\subsubsection{Demographic structure of a community and ties between individuals.}

Who meets whom? Who maintains some sort of interpersonal relationship with whom? This is one of the more global questions about sociability. An important aspect is the social hierarchy of status: how do attributes, e.g. in the domains of professional occupation or social prestige, have an influence on interpersonal ties? A classical postulate is that everybody prefers to meet another ego, someone of the same status and also similar with respect to other characteristics; such a tendency is called homophily. This postulate is confirmed in many empirical studies.

However, the existence of a relation presupposes that actors have a chance to meet, and P.Blau has shown that this chance depends upon the social composition of the local community: "our macrosociological objective is to examine how patterns of social relations in a community are affected by the social environment because the other people in their environment determine the options people have in establishing social relations" (BLAU \& SCHWARTZ, 1984, p.8). The demographic composition of the population imposes limits to interpersonal choice, regardless of value- orientations and preferences which individuals may have. The interest of such an analysis is to define statistical objective boundaries to personal choice: it is of little value to try to explain why so few people have good friends or lovers amongst a local minority, if a high proportion of love-relationships with people in this minority is simply statistically impossible.

An interesting study in this respect is MORRIS (1993), where the spread of a disease is modeled while taking into account sizes of sub-populations and differential contact rates between members of sub-populations.

\subsubsection{Normative differentiation and overlapping of social fields in a community.}

The cultural differentiation of the local community can also influence sociability. Cultural differentiation supposes that specific religious orientations, leisure activities, artistic trends, or modes of sexual behaviour have a sufficient number of supporters to reach a minimum level of collective institutionalisation through clubs, meeting places, social events, specialized shops, etc. The process of differentiation implies the emergence of various "moral milieux" (to put it in the terms of R.E.PARK) and contributes to the diversity of the urban way of life in the community 
(H.J.GANS, 1962). The question here is not the structure of the market of potential partners, like in BLAU's perspective, but the emergence of social "circles" or "contexts" in which particular activities and relationships can be legitimised even if they are marginal or disapproved of by the "silent majority". Often, but not always in the same way, cultural differentiation increases with the size of community, and it is well known that it is in the large city that original behaviours find social "niches" where they are valued: homosexual area, "hot" quarter, meeting places for exchanging couples. Thus cultural diffentiation does not have a systematic effect on the composition of personal networks. The effect of cultural differentiation of city is, rather, that a greater difference between personal networks is possible. C.S.FISCHER (1982, p.258) has shown that this effect is mediated by personal involvement: "City life seems to aid people in finding other people who share their 'most important' interest, but not in finding those who share lesser interests". Those people involved in any kind of marginal sexual life have a higher chance to find relational support and contextual legitimation of their behaviour in differentiated communities than in homogeneous communities.

Another structural property of a community is the kind of socio-spatial distribution of activities which constitute specific social fields and offer opportunities to meet people. Locations of jobs, housing, shopping areas, leisure places can be separated, in the pattern of modern "urban functional zoning", or overlapping, in the pattern of quarters of old european towns, or in some ghettos where residential, economic, and symbolic activities are gathered in the same place. If the cultural differentiation of the community allows the legitimation of different kinds of behaviour and patterns of relationships, the way in which that differentiation occurs does not determine directly the kind of social life one can have, but offers differential opportunities to get involved with others in various normative contexts or in a unique normatively homogeneous milieu. Such a differentiated community will also offer opportunities to choose between either dense interconnected or loosely knit segmented sets of interpersonal relations and contacts. Consequences of theses various opportunities shall be presented below.

\subsection{Mass communication and network effects.}

Information and knowledge is disseminated through educational activities and mass media. Today, in modern countries most people have been informed about risks of transmission of AIDS. In several countries the risks of HIV infection now are treated in biology classes in high schools. What is the effect of such information on behaviour? This effect seems to be varying, and often weak. Clearly, if networks of interpersonal relations affect how people react to the existence of the AIDS epidemic, it is not by the purely "cognitive" content.

The mediating effects of networks for information transmission are diverse. A) In the hypothesis of the "two step flow", the effect of a message is more powerful when the message is relayed by a "local" opinion leader (E. KATZ, P. LAZARSFELD, 1955); more broadly speaking, people seek differential advice from different persons in their social surrounding depending on the kind of decisions they have to make; the rapidity of adoption of an innovation depends on the number and the type of interpersonal links people have, related to the field of innovation (J.COLEMAN, E.KATZ, H.MENZEL 1966). This has a bearing mainly on questions of diffusion: people make a decision about a suggestion made in the public media because they are influenced by leaders or innovators. B) A more basic question is how the media messages are given meaning by the "receivers" through their interaction with other individuals. This question is treated in the "convergence communication model" of E.M.ROGERS and D.L.KINCAID, which addresses the issue not of "diffusion" but of "creation" and sharing of mutual understanding of an information (1979, 1981).

Interpersonal discussions are certainly influential, but this influence might be positive as well as negative from the viewpoint of prevention, and we have to explore conditions under which networks help or prevent people from having a "good" perception of and reaction to risks. The effect "B" is at least as important as the effect "A": the AIDS epidemic introduces dramatic contradictions in sexual life: love is death; absolute trust is hazardous; possible other partners of 
the sexual partner are of vital importance; and so on. The meaning and understanding of sexual life need to be reinterpreted. Ideas and values about love investments must be reorganized.

\section{Norms about safe sex.}

\subsection{Norms and sanctions.}

The information transmitted through social networks pertains not only to events such as sexual behaviour and the occurrence of disease, but also to attitudes and norms. The social network may be regarded as the structure that maintains and adapts norms through forms of social control.

What are norms? In a somewhat naive way, they can be understood as explicit, socially standardized prescriptions that actors mention when asked "what to do and what to leave?". But social reality usually deviates from this "ideal pattern". There are important gaps between explicit prescriptions, average behaviour, and abstract model. The behaviour of actors is not so much influenced by the explicit norms professed in the sub-culture as by the perceived behaviour of significant others: alter's perceived behaviour determines ego's evaluation of the validity or "seriousness" of norms.

A second question is how this influence operates, how norms arise and how they are maintained. COLEMAN (1990, p. 243) defines that "a norm concerning a specific action exists when the socially defined right to control the action is held not by the actor but by others". The norm is followed if the actor indeed carries out the action in the way that these controlling others desire. Ego's behaviour, as perceived by others in ego's personal network, may lead to a sanction: positive when the behaviour conforms to the norm, negative when it is deviant. The degree to which norms are followed depends, a.o., on the positive and negative sanctions that are applied or expected, and on internalization of the norms (which puts the controlling actors, so to say, behind the screen).

It is important to realize that people seek approval more than that they fear punishment. The influence of networks on actors is mediated to a large extent by the fact that approval by people around the actor, most importantly of "significant others", is important to him/her. In other words, the possibility for control is especially large for significant others in ego's personal network.

\subsection{How do norms come to exist and be maintained?}

As indicated above, networks can be a means to reinforce "externally" produced norms, transmitted by media. But in the network normative perspective developed here, we have to understand how and why norms are "created" by networks. COLEMAN (1990) proposes a rational perspective that tries to explain the conditions under which norms are held by individuals and groups.

In such a view, norms give rules for behaviour which are convenient or profitable for the controlling actor(s) or for the group, because of the consequences that the behaviour will have or is expected to have. A basic assumption in this model is that consequences of an actor's action are supposed to be collective as well as individual. It is because others are "interested" in the way I behave that they take control - through collective norms - on me. This basic definition of normative control fits well with contagious disease in general: the behaviour of an individual can produce effects on himself, but also on others. A first step in the elaboration of this perspective is to indicate, whose behaviour is interesting to whom. A second question is to understand how norms can be maintained. As Coleman explains, in order for norms to be realized in a social group, it is necessary that the following two collective action problems be solved: 
(1) actors must be brought so far that they comply with the norm, even though it is individually irrational for them to do so (each actor would be better off if everybody else complied with the norm, but he alone did as he liked);

(2) actors must be brought so far that they apply sanctioning to uphold the norm, even though each actor would be better off if the burden to apply sanctions was borne by all others without him.

These two problems are called by Coleman the first- and the second-order public-good problem. Solving the second-order problem is of fundamental importance for solving the firstorder problem, because the expectation of sanctions often is crucial in order to get individuals to comply with the norm. Whether individuals are willing to comply with the norm and willing to sanction in order to uphold the norm (i.e., whether the first- and second-order public-good problem for a specific norm can be solved), depends for a great deal on the individuals' expectations about the consequences of their actions. Some aspects will be mentioned that have a bearing on conditions for the solution of the first- and second-order public-good problems for norms about safe sex.

Whether a person will comply with a norm about safe sex will depend on:

* a "classical" individual advantages-costs evaluation of the sexual behaviour itself and its modalities, which depends, among others, on his/her perception of risks;

* plus the specific advantages-costs evaluation of the expected relational sanctions.

The second points adds the cost of relational sanctions to the usual model of evaluation. The pressure exerted by such sanctions, or the threat implied by their possibility, can be the stronger when this pressure is exerted in the social field itself in which the sexual relations are embedded - e.g., the social circle of friends.

In this analysis of norms concerning safe sex it is important to identify a) who is "interested" by the sexual behaviour of another individual, and b) who is the person who might apply sanctions. We call ego the person whose sexual behaviour is under consideration, and alter the potential sanctioner. As COLEMAN (1990) stresses, it is not at all automatic for alter to sanction ego's behaviour. Usually, there are costs attached to carrying out a sanction; alter may find these costs too high and hope that somebody else will perform the sanction. Whether alter applies a sanction when he/she perceives a violation of the norm will depend to a large extent on the costs and benefits to alter of ego's norm violation and of alter's sanction.

As possible sanctioners of non-safe sexual behaviour, different roles are played by steady sexual partners, potential sexual partners, and friends or acquaintances who are not viewed by ego as a potential partner.

a) Actual and potential sexual partners.

Sexual partners have a special role as holders of norms. For his own health, for the quietness and trust of the sexual exchange with ego, alter is interested by ego's behaviour. Alter may find it in his/her interest that ego have no sexual relations at all with third persons, but this is not the focus of our present discussion. If ego does have sexual relations with third persons, overtly or covertly, then it clearly is in alter's interest that ego's behaviour is "safe". This implies that alter's problem is to know and control the modalities of ego's relations with third persons. For his own interest she/he has first to obtain reliable information on ego's behaviour. In an open sexual market it is problematic to obtain such information. Secondly, if necessary, alter may try to change ego's behaviour, by sanctions such as - showing disapproval;

- refusing unprotected sexual intercourse with ego; - finally, refusing ego any kinds of sex.

Thess sanctions, however, may be costly in terms of sexual pleasure foregone and in terms of endangering alter's relationship with ego.

If reliable informations on ego's relations with third persons cannot be obtained, and/or if alter does not want to engage the possible personal cost of sanctions against a potential lovable sexual partner, then alter's interest needs the intervention of another person. A possible way to obtain such interventions is that alter tries to promote in his social surroundings some kind of safe sexual conduct. This implies that alter is interested in the general existence, and 
maintenance, of a "network norm" of safe sexual conduct. If such a norm is followed, than alter does not have to bear the risks of sanctioning her/his sexual partner.

There also exists a weaker form of this norm of safe sexual conduct. If ego is part of a social network of persons who are not infected, and all these persons' sexual relations are either within this "healthy" network, or (for relations with "outsiders") with safe sexual behaviour, then ego's health is not endangered by sexual contacts. Such a system implies a collective job of gatekeeping: seeing to it that the network remains "endogamous"; or, less strictly, seeing to it that if members of the network have sex with non-members, they do protect themselves.

b) Alters who are close friends.

For alters who are not potential sex partners (or not perceived as such), their interest is to have no close friend nor acquaintance infected by the virus, simply because they are attached to them (some might be viewed more distantly as a potential sexual partner). How can they control these friends?

Two forms of sanction are possible here. A direct negative sanction is by showing disapproval to ego as a friend. Indulgence is a value often attached to friendship, and it is often thought that friends should not condamn each other; but friends may have the feeling that, in these cases, criticism means help and solidarity rather than rejection. Further, the sensitive nature of an issue such as sexuality implies that when alter sanctions by exhibiting disapproval this can be perceived by ego as meddling with his personal affairs. On the other hand, friends often are the rare persons allowed to be informed of such personal affairs. So the values in question are ambiguous, and sanctioning can be costly to alter. A second kind of sanction is more diffuse. Alter could simply tell ego's other friends, acquaintances, or potential sex partners, that he disagrees with ego's sexual life. This is not a very nice but in some cases a quite rational reputational sanction. However, it creates a contradiction: trust and fairness are basic components of friendship.

Again, alter's interest is that his/her friends could be controlled and under pressure of sanction by others than him. But here the cost of sanctioning decreases compared to the previous case.

c) Weak ties and control.

Potential sexual partners and close friends are interested in the behaviour and the health of ego. To sanction ego directly is costly for them. The supplementary output of the existence of a network norm is the escape from the contradiction that the sanctioning endangers the very relationship for the security of which the sanctions would be applied. But it is difficult to solve the "second order public-good problem", necessary for maintaining the norm: for whom are the advantages of sanctioning large enough to overcome their costs?

The costs may be lower when the control operates through weak ties in the network. Especially the "gatekeeper's" job, mentioned above, seems possible for social friendship relations that can be characterized as weak ties: these loose friends can try to prevent sexual relations of acquaintances outside the "safe endogamous" network. Information on sexual relations themselves ("who sleeps with whom") is transmitted with less difficulties in the network than information about the precautions taken; so it is less difficult to reduce the frequency of sexual relations with others outside the "safe" network, than to control the safety of such relations, once they are there. The weakness of the tie does not decrease the importance of the sanction, because the sanction may be mainly reputational: the controller might speak to others in the network. For the controller the cost is low because the tie is weak. For the controller the advantage may be important: others can be grateful to him, first for having given information important for their own interest, secondly for having imposed a sanction wich could have been of very high cost to themselves. 


\subsection{Information and norms on sexual behaviour in social networks.}

As we have seen, information is a particularly problematic aspect of maintaining norms about safe sexual conduct. Information is necessary if a sanction on unsafe sexual activities is to be applied; in addition, information about what is going on will be helpful for the sanctioner to get support from third persons, and thus decrease the costs of sanctioning. Thus, information is crucial to solve the first-order as well as the second-order public good problem.

In the domain of emotional and sexual affairs, we have to address a preliminary and basic question: which aspects of an individual's sexual behaviour are known to certain members of his/her intimate or wider social environment; how truthful is this knowledge; and how fast, and with which distortions, is this knowledge further transmitted through the social network?

Close relationship, common leisure activities, allow members of the personal network of an individual to know the kind of sexual partners exhibited socially by this individual; but no more. Other sexual partners can be "dissimulated" to the day-to-day network of acquaintances. At the other end of the spectrum, sexual exploits and, sometimes, sexual practices, are in many subcultures a domain of boasting and window-dressing. From the point of view of prevention, the "hidden" sexual activities, which are outside the reach of direct social control, are particularly important; while on the other hand overt braggart communication about sexual activities may have a nefarious effect on perceptions, expectations, and norms.

People can talk and disclose to specific others some dimensions of their private life. A methodological test has shown that people agree to describe with whom, and in what kind of relations, they discuss about sexual and emotional affairs; and how they themselves perceive the sexual behaviour of these "confidents" (FERRAND, 1991; FERRAND and MOUNIER, 1993). Results of such questions integrated in the French national survey on sexual behaviours (A.SPIRA, N.BAJOS and ACSF Group 1993) indicate that 53\% of men and 69\% of women have at least one person with whom they talk about love and sex affairs. Confidents are mainly friends (same age 37\%, different 24\%), kin (24\%), colleagues (14\%). Compared with other data on sociability (HERAN, 1988) this shows that not all alters nor all kinds of relation are equally able or allowed to transmit such informations.

Norms about the transmission of information about sexual practices can be quite different in different social contexts or social circles.

First, norms can prescribe actors to exchange more or less, and more or less truthful, information regarding the kind of social and sexual life they have. The availability of information depends largely on how free people are in talking about sex. As a consequence, we can predict that norms on safe sex will be stronger in contexts and sub-cultures with freedom in talking about sex than in sub-cultures with a taboo on frank talking about sex; under the condition, of course, that the perceived risks of HIV infection are not negligible. This prediction has an important consequence for prevention: promoting a free atmosphere to talk about sex and sexual experiences in general, without a necessary reference to HIV or other sexually transmitted diseases, must be an important ingredient in AIDS prevention campaigns. At the opposite side of the continuum, people involved in married or otherwise steady sexual relationships are often in a context where there exist norms prohibiting a) any promiscuity or extra-marital sex; b) any explicit discussion about sex. In such a context there is no established form for applying social pressure, even if "accidents" occur.

Secondly, social control and possible pressure exerted by the network, or portions of it, depend upon the roles that alters can have with respect to ego: the available information, the costs of sanctioning, as well as the effects of the sanctions on ego, depend on these roles. The role, and the kind of social context in which a given aspect of the sexual conduct of ego is known, can facilitate or prohibit the intervention by alter in his "personal" or "sexual" affairs. For example, coworkers can "do as if" they know nothing, when friends feel legitimized to say something, and members of the family feel compelled to give explicit advice. So, advice as well 
as control by the network depends upon the kind of relation between the person and the potential "advisor" or "controller".

\subsection{Network structure and information flow.}

As sanctioning presupposes information about ego's sexual behaviour, ego may see it to be in his interest not to give certain information. He can try to manage the information about his person that is transmitted through the network in such a way that approval is maximal and negative sanctions are minimized. However, this management presupposes certain structural properties of the network, which depend upon global features of the community.

The more differentiated and the more segmented a community, the more an actor can meet culturally and normatively diverse persons. But also the more he/she can manage his relations in such a way that the persons he/she knows do not know each other (segmented personal network). Then, (a) he can play different roles; (b) it is possible that his (sexual) relations are under control and approval of only one part of his network. Diverse or even contradictory behaviours are allowed for the same actor if he/she separates his life through various circles and special networks, each able to be informed of, and to recognize only one aspect of his personal diversity.

On the contrary, the overlapping of sexual networks and the networks of personal friends and acquaintances has important effect on the functioning of social pressure. (a) If sexual and non-sexual relations are to some extent mixed in the same network, members can feel more concerned by others' love relationships. For example, networks of friends - where potential sexual partners often are met - are, in many cases, deeply concerned with the sexual life of individuals. In such networks, a norm of free talk can exist more easily. (b) Overlapping also "mechanically" facilitates the circulation of information; (c) as we have seen previously, it allows diverse actors to share the burden of sanctioning.

Until now, most people who find sexual partners in their day-to-day network of friends, behave as if there is no risk because their day-to-day contacts imply knowledge and trust in nonsexual affairs. This kind of situation and behaviour may be considered dangerous. On the other hand, we can expect that it is also in such structural overlapping of acquaintance and sexual networks that norms of safe sex have a higher chance to be collectively upheld.

\subsection{Communication and the emergence of norms.}

It is clear to everybody that risk perception is important for norms about sexual protection. This has a paradoxical consequence (which is generally present in many questions about the existence of a norm that serves to protect a social group from risks from within the group): the norm can only be maintained if it is perceived as not being maintained perfectly. If none of ego's potential sex partners is supposed to have risky sexual contacts then not only is it superfluous for ego to comply with the norm, but it is also superfluous for ego to exert himself to maintain the norm. (If ego cares not only for his own health but also for the health of his friends, then the condition extends also to his friends' potential sex partners.) In other words: precisely the networks with the more generalized sexual exchange (the more sexually "liberal" and, at the beginning of the epidemic, the more "dangerous" ones) are the more interested to maintain strict norms of safe sexual conduct and reciprocal control. This means also that it can be predicted that as soon as information about one case of an infected person in a network of potential sexual "clean" partners begins to spread, more strict norms will emerge.

In social networks of individuals some of whom engage in sexual relations that are not strictly endogamous, "general" informations about the AIDS epidemic, but more certainly specific information on particular cases of infection, will lead to changes in norms about sexual behaviour. The eventual pressure in such a social network towards changes in norms must be 
great, because unsafe sexual behaviour by other persons, even by persons who may be completely unknown to ego, increases the perceived probability that ego will be infected by the HIV virus. This hypothesis does not suggest that an individual's sexual behaviour is directly affected by the fact of knowing someone infected by HIV. It only says that collective normative pressure will increase with the number of people in the network of friends and sex partners, informed about significant cases of HIV infected persons. It is for fundamental ethical reasons that public campaigns urge people not to reject seropositive persons. Nevertheless it is also possible to suggest that as seropositive people are approached in a more open and friendly way, the communication about sexual behaviour and risk will also be more open and norms of safe sexual behaviour will be more strongly supported.

\section{Conclusion.}

This paper presents an attempt to approach social life and sexual life not as different domains which interact but as two dimensions of the same reality: networks of interpersonal relations. Networks are constrained by broader community contexts and they constrain individuals' relational strategies. Four major functions are fulfilled by networks:

- relay and personalisation of public campaign messages;

- "market" of potential sexual partners;

- channel of informations about personal life;

- producer and support of collective norms.

The approach presented here is not satisfied to treat norms as a kind of exogenous independent variable that can be taken as given, and of which the power and influence on the individual level must be studied. Collective norms are not prescribed by medical or public health agencies, but maintained by groups and networks, on the basis of some collective interest (in the past or present) in their application.

In love relations, because love is love, sexual partners are not necessarily interested only by their own interest, but others as alters, in a more detached and cool appreciation of what is going on, are also interested by the health of friends or former and future mates.

AIDS prevention is recognized as a public issue, because this disease endangers the population. On the other hand, sexual life is seen as a private issue. The way in which the question is often addressed opposes the duty of the State to the freedom of individuals. The basic idea which can be taken from the model presented here, is that an intermediate level exists: networks. Because of networks of friends and acquaintances, the behaviour of lovers can be something which interests people around them. A first conclusion is that we have to mind not only how lovers engage their private relation, but also how people around them a) are in fact concerned by that relation; b) can exert a pressure on them into the direction of safe behaviour. If we should summarize this in a slogan, it would be something like "Help your friends to keep clean".

From this perspective we have tried to point out some properties of networks which facilitate or impede the emergence of collective norms of safe sexual conduct. The model suggests that the overlapping of friendship and sexual networks is important. But this overlap appears often spontaneously in social life. Another theoretical result can be summarized in a brief sentence: to prevent the spread of HIV, information about personal life must spread through interpersonal networks. A second conclusion, therefore, is that it is important to recommend frank talks as well as french letters. 


\section{REFERENCES}

1984 BLAU P.M. SCHWARTZ.J.E. Crosscutting social circles. Orlando, Academic Press. 1966 COLEMAN J.S., KATZ E., MENZEL H., Medical innovation: a diffusion study. New York, Bobbs-Merril.

1990 COLEMAN J.S. Foundations of social theory, University of Chicago Press.

1991 FERRAND A. La confidence: des relations au réseau. Sociétés Contemporaines, N5, p. 720.

1993 FERRAND A., MOUNIER L. Paroles sociales et influences normatives. Ch. 6 in SPIRA, BAJOS, et le groupe ACSF Les comportements sexuels en France, Paris, La Documentation Française, p.171-179..

1962 GANS H. Urbanism and suburbanism as a way of life. A re- evaluation of definitions. in Rose ed, Human behaviour and social process. London, Routledge and Kegan Paul.

1988 HERAN F. La sociabilité, une pratique culturelle. Economie et statistique, N.216, Pp.3-22. 1955 KATZ E., LAZARSFELD P. Personal influence. New York, Free Press.

1993 MORRIS M. Epidemiology and social networks: modeling structured diffusion. Sociological Methods and Research, vol. 22, 99 - 126.

1992 PETO D. REMY J. VAN CAMPENHOUDT L. HUBERT M. Modes d'adaptation au risque du Sida dans les relations héterosexuelles. Bruxelles, Centre d'Etudes Sociologiques.

1979 ROGERS, E.M. in HOLLAND P.W. and LEINHARDT S. Perspectives on social networks, New York, Academic Press.

1981 ROGERS, E.M. KINCAID D.L., Communication networks. Toward a new paradigm for research. New York, The Free Press.

1993 SPIRA, A., BAJOS N. et le groupe ACSF. Les Comportements sexuels en France. Paris, La Documentation Française. 